\section{AB022. Biologics and vaccination: relationship of influenza, pneumonia and zoster}

\section{Deep Patel ${ }^{1}$, Steven Maczuga ${ }^{2}$, Matthew Helm², Galen Foulke ${ }^{2}$}

${ }^{1}$ Penn State Hershey College of Medicine, ${ }^{2}$ Penn State Hershey Department of Dermatology, Hershey, PA, USA

Correspondence to: Deep Patel. 500 University Drive, HU14, Hershey, PA 17033, USA. Email: dpatel3@pennstatehealth.psu.edu.

\begin{abstract}
The use of biologics for inflammatory skin disease is increasing. Although manufacturers recommend pneumococcal, influenza and varicella zoster vaccines in patients treated with tumor necrosis factor inhibitors to mitigate the risk of infection, data regarding adherence in this group of patients is limited. The European League Against Rheumatism and American College of Rheumatology also issued the recommendations to advocating for influenza, pneumococcal pneumonia and Zoster for this high-risk patient group. We queried the MarketScan data base (which includes about 47 million people) to determine rates of vaccination and infection. In 2014, we identified 41,607 patients, aged 18-60 on adalimumab, etanercept or infliximab (TNFi) for 6 months or more. Of these patients, only 157 received a pneumococcal vaccine. We will present similar data describing utilization of influenza and zoster vaccination in psoriatic utilizing TNFi, from 2014-2016. Rates of in
\end{abstract}

relevant infection (influenza, pneumonia and varicella) will be compared between vaccinated and unvaccinated biologic users. We hypothesize that immunosuppression due to biologic therapy (specifically TNF-inhibitors) incurs a higher risk of infection. Our preliminary data likely highlight an important practice gap in the use of TNFi within dermatology. Teaching points: biologics are associated with a higher risk of influenza, pneumococcal pneumonia, and varicella zoster. Although infection can lead to significant morbidity and mortality, vaccination prior to the initiation of biologic therapy can mitigate risk. Vaccination is probably underutilized in these patients.

Keywords: Vaccination; tumor necrosis factor inhibitors; influenza; varicella zoster; pneumococcal pneumonia

doi: 10.21037/atm.2021.AB022

Open Access Statement: This is an Open Access article distributed in accordance with the Creative Commons Attribution-NonCommercial-NoDerivs 4.0 International License (CC BY-NC-ND 4.0), which permits the noncommercial replication and distribution of the article with the strict proviso that no changes or edits are made and the original work is properly cited (including links to both the formal publication through the relevant DOI and the license). See: https://creativecommons.org/licenses/by-nc-nd/4.0/.

Cite this abstract as: Patel D, Maczuga S, Helm M, Foulke G. Biologics and vaccination: relationship of influenza, pneumonia and zoster. Ann Transl Med 2021;9(5):AB022. doi: 10.21037/ atm.2021.AB022 